\title{
Inhibition of solution-processed $1,4,5,8,9$, 11-hexaazatriphenylene-hexacarbonitrile crystallization by mixing additives for hole injection layers in organic light-emitting devices
}

\author{
Satoru Ohisa, Yong-Jin Pu, Shogo Takahashi, Takayuki Chiba and Junji Kido
}

\begin{abstract}
We report the inhibition of solution-processed 1,4,5,8,9,11-hexaazatriphenylene-hexacarbonitrile (HAT-CN) crystallization by mixing additives for the hole injection layers (HILs) in organic light-emitting devices (OLEDs). Various additives were mixed with the HAT-CN layer, including acrylates, compounds resembling HAT-CN and arylamine derivatives. Among these, the HAT-CN films mixed with ditrimethylol propane tetraacrylate (AD-TMP) and pyrazino[2,3-f][1,10]phenanthroline-2,3-dicarbonitrile (PPDN) showed a transparent appearance and high solvent resistances. The former was ascribed to the inhibition of the crystallization. We used these additives for the preparation of electron acceptor layers in charge generation layers (CGLs) of the CGL-only devices. The device prepared by mixing HAT-CN with PPDN showed a lower driving voltage and was applied to the production of an HIL in a solution-processed OLED. The device showed a lower driving voltage and a higher luminescent efficiency than those of the device containing a conventional HIL, poly(3,4-ethylenedioxythiophene)/poly(4-styrenesulfonate) (PEDOT:PSS). Polymer Journal (2017) 49, 149-154; doi:10.1038/pj.2016.92; published online 28 September 2016
\end{abstract}

\section{INTRODUCTION}

Organic light-emitting devices (OLEDs) have attracted a great deal of attention as the next generation of energy-saving display and lighting devices required for a low-carbon society. ${ }^{1-3}$ To fabricate highly efficient devices, the incorporation of hole injection layers (HILs) is indispensable because these significantly improve the characteristics of hole injection from the anode to the emitting layer, leading to lower driving voltages and improved charge recombination balance. To date, various HILs have been reported, ${ }^{4-15}$ and, among these, $1,4,5,8,9$, 11-hexaazatriphenylene-hexacarbonitrile (HAT-CN) has been employed in HILs (leading to low driving voltage) ${ }^{4,16-22}$ since the first application of OLED by LG Chemical Ltd. ${ }^{22}$ HAT-CN was first reported by Czarnik and co-workers ${ }^{23}$ and its characterization has been investigated in various studies. ${ }^{24-29}$ The most remarkable property of HAT-CN is the extremely deep energy level of its lowest unoccupied molecular orbital. Six nitrile groups attached to a heterocyclic moiety generate a large electron withdrawal effect from the heterocycle, making it a strong acceptor. Electron affinity $(E A)$ values ranging from 5.7 to $6.1 \mathrm{eV}$ have been reported. ${ }^{30-31}$ In OLEDs, HAT-CN is usually adjacently arranged to the hole transporting materials (HTMs) such as 4,4'-bis[ $N$-(1-naphthyl)- $N$-phenyl-amino] biphenyl ( $\alpha$-NPD). When applying an electric field to the HAT-CN/ HTM bilayer, an electron is injected from the highest occupied molecular orbital of HTM to the lowest unoccupied molecular orbital of HAT-CN, thereby generating electron/hole charge pairs at the interface, with HTM functioning as an electron donor material and HAT-CN functioning as an electron acceptor material. Consequently, HAT-CN functions as an HIL. The injected hole is transported through the HTM, whereas the injected electron is transported through HAT-CN with a mobility of $2.5 \times 10^{-4} \mathrm{~cm}^{2} \mathrm{~V}^{-1} \mathrm{~s}^{-1} .27$ Therefore, HAT-CN has attracted attention as an HIL-reducing driving voltage agent.

Solution-processed HILs are advantageous for the fabrication of large-area devices and are also effective for the suppression of leakage currents and improvement of device yields. The applications of HAT-CN to solution-processed HILs are desired. Unfortunately, solution-processed HAT-CN crystallizes easily. In conventional bottom emission-type OLEDs, HILs are required to have a very low surface roughness because a rough surface induces device shorts while decreasing device yields. Crystallized films usually have very rough surfaces with hazy appearance, thereby making them unsuitable for HILs in OLEDs. Several approaches to prevent crystallization exist. For example, one approach involves fast drying of the coated solution. Lin et al. $^{21}$ reported on the solution-processed HAT-CN films formed from acetone solutions that enabled fast evaporation because of its low boiling point. A thin layer $(4 \mathrm{~nm})$ was formed with a root mean square roughness of $2.82 \mathrm{~nm}$. This relatively large root mean square value was ascribed to the formation of HAT-CN nanoaggregates. These authors 
applied the HAT-CN layer to HILs in OLEDs. The OLEDs exhibited excellent device performances because of the high hole injection characteristics upon insertion of the solution-processed HAT-CN layer. Although the obtained results were good, the utilization of acetone as a coating solution is difficult because the solvent evaporation rate is too high to control, lowering the robustness of thickness control during mass production. Therefore, an alternative approach allowing the inhibition of HAT-CN crystallization is required.

Herein, we report an alternative approach to inhibiting crystallization of solution-processed HAT-CN films. We mixed various additives with the HAT-CN layer, including acrylates, compounds resembling the HAT-CN chemical structure and arylamine derivatives. We utilized tetrahydrofuran as a solvent because it is a good solvent for various types of additives. HAT-CN layers mixed with some of these additives were transparent that was ascribed to the inhibition of HAT-CN crystallization. Furthermore, we evaluated solvent resistance of the HAT-CN films to the stacking of the HTM by the solution process. Among the additives studied, the HAT-CN films with ditrimethylol propane tetraacrylate (AD-TMP) and pyrazino[2,3-f] $[1,10]$ phenanthroline-2,3-dicarbonitrile (PPDN) showed both a transparent appearance and high solvent resistance. We used them as electron acceptor layers in charge generation layer (CGL)-only devices. The device containing the HAT-CN mixed with PPDN showed the lowest driving voltage. Finally, we used the HAT-CN mixed with PPDN as an HIL in a solution-processed OLED. This device showed a lower driving voltage and higher luminescent efficiency compared with the device containing the conventional HIL, poly(3,4-ethylenedioxythiophene)/poly(4-styrenesulfonate) (PEDOT:PSS).

\section{EXPERIMENTAL PROCEDURE}

\section{Materials}

HAT-CN, 1,3,5-tris(1-phenyl-1H-benzimidazol-2-yl)benzene (TPBi) and 8-quinolinolato lithium (Liq) were purchased from e-Ray Optoelectronics Technology Co., Ltd (Taoyuan, Taiwan). 4,4',4"-Tris(3-methylphenylphenylamino)triphenylamine ( $m$-MTDATA), $N, N^{\prime}$-di-1-naphthalenyl- $N, N^{\prime}$-diphenyl$\left[1,1^{\prime}: 4^{\prime}, 1^{\prime \prime}: 4^{\prime \prime}, 1\right.$-quaterphenyl]-4,4-diamine (4P-NPD), 4,4'-bis(2,2-diphenylvinyl)$1,1^{\prime}$-biphenyl (DPAVBi), PPDN and $N, N^{\prime}$-(biphenyl-4,4'-diyl)bis $\left(N, N^{\prime}, N^{\prime}-\right.$ triphenylbiphenyl-4, $4^{\prime}$-diamine) (TPT1) were purchased from Luminescence Technology Corp. (Hsin-Chu, Taiwan). $\alpha$-NPD was purchased from Chemipro Kasei Kaisha, Ltd (Hyogo, Japan). Poly[ $N, N^{\prime}$-bis(4-butylphenyl)- $N, N^{\prime}$-bis(phenyl)-benzidine] (poly-TPD) was purchased from American Dye Source, Inc. (Montreal, QC, Canada). 9,9'-Diphenyl-6-(9-phenyl-9H-carbazol-3-yl)$9 \mathrm{H}, 9^{\prime} \mathrm{H}-3,3^{\prime}$-bicarbazole (TrisPCz) was obtained from Hodogaya Chemical Co., Ltd (Tokyo, Japan). PEDOT:PSS (CH8000) was purchased from Heraeus Materials Technology (Hanau, Germany). 2,3,8,9,14,15-Hexa-fluoro5,6,11,12,17,18-hexaazatrinaphthylene (HATNA- $\mathrm{F}_{6}$ ) was synthesized as reported elsewhere. ${ }^{32} \mathrm{AD}-\mathrm{TMP}$ was purchased from Shin-Nakamura Chemical Co., Ltd (Wakayama, Japan). $\mathrm{ZnO}$ layer was coated using $\mathrm{ZnO}$ nanoparticles synthesized according to the previously reported procedures. ${ }^{33,34}$ Indium tin oxide (ITO) on glass substrates were purchased from Asahi Glass Co., Ltd (Tokyo, Japan). All solvents were purchased from commercial providers.

\section{HAT-CN crystallization inhibition and solvent resistance tests}

Mixtures $(10 \mathrm{mg}$ ) composed of HAT-CN and additives were dissolved in $4 \mathrm{ml}$ of tetrahydrofuran. AD-TMP was mixed at 1, 5 and $10 \mathrm{wt} \%$ into the total volume of $10 \mathrm{mg}$. The other additives (that is, HATNA-F, PPDN, $m$-MTDATA and 4P-NPD) were mixed at $10 \mathrm{wt} \%$ into the total volume of $10 \mathrm{mg}$. The films for the tests were fabricated using the solutions, and the fabricated films are listed in Table 1. The solutions were spin coated on quartz substrates at 4000 r.p.m. for $30 \mathrm{~s}$ and annealed at $70^{\circ} \mathrm{C}$ for $10 \mathrm{~min}$ (films 5, 7, 9 and 10 ) or $180^{\circ} \mathrm{C}$ for $1 \mathrm{~h}$ (films $1-4,6$ and 8 ) in $\mathrm{N}_{2}$ atmosphere. HAT-CN crystallization was visually evaluated by checking the haziness of transparency of the fabricated films. Solvent resistance tests were conducted by rinsing the films
Table 1 Appearances and solvent resistances of the solutionprocessed HAT-CN mixed with additives

\begin{tabular}{lccccc}
\hline & & \multicolumn{5}{c}{$\begin{array}{c}\text { Annealing tem- } \\
\text { Film }\end{array}$} & Additive & Concentration & perature $\left({ }^{\circ} \mathrm{C}\right)$ & Appearance & $\begin{array}{c}\text { Solvent } \\
\text { resistance }\end{array}$ \\
\hline 1 & - & - & $180^{\circ} \mathrm{C}$ & Hazy & $+{ }^{\mathrm{b}}$ \\
2 & AD-TMP & $1 \mathrm{wt} \%$ & $180^{\circ} \mathrm{C}$ & Hazy & + \\
3 & AD-TMP & $5 \mathrm{wt} \%$ & $180^{\circ} \mathrm{C}$ & Transparent & ++ \\
4 & AD-TMP & $10 \mathrm{wt} \%$ & $180^{\circ} \mathrm{C}$ & Transparent & ++ \\
5 & HATNA-F 6 & $10 \mathrm{wt} \%$ & $70^{\circ} \mathrm{C}$ & Transparent & - \\
6 & HATNA-F 6 & $10 \mathrm{wt} \%$ & $180^{\circ} \mathrm{C}$ & Transparent & - \\
7 & PPDN & $10 \mathrm{wt} \%$ & $70^{\circ} \mathrm{C}$ & Transparent & - \\
8 & PPDN & $10 \mathrm{wt} \%$ & $180^{\circ} \mathrm{C}$ & Transparent & ++ \\
9 & m-MTDATA & $10 \mathrm{wt} \%$ & $70^{\circ} \mathrm{C}$ & Transparent & - \\
10 & 4P-NPD & $10 \mathrm{wt} \%$ & $70^{\circ} \mathrm{C}$ & Transparent & - \\
\hline
\end{tabular}

Abbreviations: AD-TMP, ditrimethylol propane tetraacrylate; HAT-CN, 1,4,5,8,9,11-hexaazatriphenylene-hexacarbonitrile; HATNA- $F_{6}$, 2,3,8,9,14,15-hexa-fluoro-5,6,11,12, 17, 18-hexaazatrinaphthylene; $m$-MTDATA, 4,4',4"-Tris(3-methylphenylphenylamino)triphenylamine; 4P-NPD, ( $N, N^{\prime}$-di-1-naphthalenyl- $N, N^{\prime}$-diphenyl-[1, $1^{\prime}: 4^{\prime}, 1^{\prime \prime}: 4^{\prime \prime}, 1$-quaterphenyl]-4,4-diamine PPDN, pyrazino[2,3-f][1,10]phenanthroline-2,3-dicarbonitrile.

PPDN, pyrazino[2,3-f][1,10]phena
aThe films were rinsed in $p$-xylene.

$b_{++}$insoluble, + , slightly soluble, - , soluble.

using p-xylene. Using a Shimadzu UV-3150 UV-vis-NIR spectrophotometer, ultraviolet-visible absorption spectra of the films were measured before and after rinsing.

\section{Device fabrications}

CGL-only devices with a structure of (ITO/ZnO $(10 \mathrm{~nm}) /$ electron acceptor layer $(10 \mathrm{~nm}) / \alpha$-NPD $(100 \mathrm{~nm}) / \mathrm{Al})$ were fabricated. The electron acceptor layers were HAT-CN mixed with the $10 \mathrm{wt} \%$ AD-TMP (devices A-1 and 2), $10 \mathrm{wt} \%$ PPDN (devices A-3 and 4), $10 \mathrm{wt} \% \mathrm{~m}$-MTDATA (device A-5) and $10 \mathrm{wt} \% 4 \mathrm{P}-\mathrm{NPD}$ (device A-6) formed by the spin-coating method. Evaporated HAT-CN was also used (device A-7). The HAT-CN:10 wt\% AD-TMP layers were annealed at $70^{\circ} \mathrm{C}$ for $10 \mathrm{~min}$ (device A-1) or $180^{\circ} \mathrm{C}$ for $1 \mathrm{~h}$ (device A-2). The HAT-CN: $10 \mathrm{wt} \%$ PPDN layers were annealed at $70{ }^{\circ} \mathrm{C}$ for $10 \mathrm{~min}$ (device A-3) or $180^{\circ} \mathrm{C}$ for $1 \mathrm{~h}$ (device A-4). The HAT-CN:10 wt $\%$ $m$-MTDATA and HAT-CN: $10 \mathrm{wt} \%$ PP-NPD layers were annealed at $70{ }^{\circ} \mathrm{C}$ for $10 \mathrm{~min}$. The $\mathrm{ZnO}$ layer was formed by the spin-coating method using a liquid nanoparticle dispersion, and the $\alpha$-NPD $(100 \mathrm{~nm})$ and $\mathrm{Al}$ layers were formed by evaporation under high vacuum. OLEDs were fabricated with a structure of (ITO/HIL/poly-TPD $\quad(40 \mathrm{~nm}) / 10 \mathrm{wt} \% \quad$ DPAVBi: $45 \mathrm{wt} \%$ TPT1:45 wt $\%$ TrisPCz $(30 \mathrm{~nm}) / \mathrm{TPBi}(50 \mathrm{~nm}) / \mathrm{Liq}(3 \mathrm{~nm}) / \mathrm{Al})$. The applied HILs were HAT-CN:10 wt $\%$ PPDN (10 nm) (device B-1), and a conventional hole injection material PEDOT:PSS $(30 \mathrm{~nm}$ ) (device B-2) was formed by the spin-coating method. The HAT-CN:10 wt $\%$ PPDN layer was annealed at $180{ }^{\circ} \mathrm{C}$ for $1 \mathrm{~h}$ in $\mathrm{N}_{2}$ atmosphere. PEDOT:PSS layer was annealed at $200{ }^{\circ} \mathrm{C}$ for $10 \mathrm{~min}$ in air atmosphere. With the exception of Liq and Al layers, each layer in the system was formed by the spin-coating method. The Liq and Al layers were formed by evaporation under high vacuum. The spin-coating and postannealing processes were conducted in $\mathrm{N}_{2}$ atmosphere. Poly-TPD functioning as the hole transporting layer was formed from a chlorobenzene solution and was subsequently annealed at $160{ }^{\circ} \mathrm{C}$ for $30 \mathrm{~min}$. The $10 \mathrm{wt} \%$ DPAVBi:TPT1: TrisPCz as the emissive layer was formed from an ester solution and annealed at $130{ }^{\circ} \mathrm{C}$ for $10 \mathrm{~min}$. TPBi functioning as the electron transporting layer was formed from a methanol solution and annealed at $60^{\circ} \mathrm{C}$ for $10 \mathrm{~min}$. The fabricated devices were encapsulated in glass caps with ultraviolet-cured resins and oxygen getters. The sizes of the emission area were $2 \mathrm{~mm} \times 2 \mathrm{~mm}$ in all cases. The current density-voltage $(J-V)$ and luminance-voltage characteristics of OLEDs were measured using a current source Keithley 2400 (TEKTRONIX, INC., Tokyo, Japan) and a luminance meter Konica Minolta CS-200 (Tokyo, Japan), respectively. Electroluminescence spectra were measured using a spectral radiance meter Konica Minolta CS-2000. Quantum efficiencies were calculated using the Lambertian assumption. 
<smiles>N#Cc1nc2c(nc1N)c1nc(C#N)c(C#N)nc1c1nc(C#N)c(C#N)nc21</smiles>

HAT-CN<smiles>Fc1cc2nc3c4nc5cc(F)c(F)cc5nc4c4nc5cc(F)c(F)cc5nc4c3nc2cc1F</smiles>

HATNA-F6<smiles>C=CC(=O)OCC(CC)(COCC(CC)(COC(=O)C=C)COC(=O)C=C)COC(=O)C=C</smiles>

AD-TMP<smiles>N#Cc1nc2c3cccnc3c3ncccc3c2nc1C#N</smiles>

PPDN<smiles>c1ccc(N(c2ccc(-c3ccc(-c4ccc(N(c5ccccc5)c5cccc6ccccc56)cc4)cc3)cc2)c2cccc3ccccc23)cc1</smiles>

4P-NPD<smiles>Cc1cccc(N(c2ccccc2)c2ccc(N(c3ccc(N(c4ccccc4)c4cccc(C)c4)cc3)c3ccc(N(c4ccccc4)c4cccc(C)c4)cc3)cc2)c1</smiles>

Figure 1 Chemical structures of 1,4,5,8,9,11-hexaazatriphenylene-hexacarbonitrile (HAT-CN) and the additives.

\section{RESULTS AND DISCUSSION}

Inhibition of HAT-CN crystallization by mixing additives

Chemical structures of HAT-CN and the additives are shown in Figure 1 . The inhibition effects obtained by mixing the additives are summarized in Table 1. The HAT-CN-only film (film 1) showed a hazy appearance ascribed to HAT-CN crystallization. Then, we mixed AD-TMP with HAT-CN at 1, 5 and $10 \mathrm{wt} \%$ concentrations (films 2-4). After spin coating, the films were annealed at $180^{\circ} \mathrm{C}$ for $1 \mathrm{~h}$ in $\mathrm{N}_{2}$ atmosphere to allow the reaction of the acryl groups of AD-TMP. Nevertheless, film 2 still showed a hazy appearance. On the other hand, films 3 and 4 containing higher concentrations of AD-TMP than film 2 showed transparent appearances, thereby suggesting that the mixed AD-TMP inhibited HAT-CN crystallization. We found that mixing at concentrations of $\geqslant 5 \mathrm{wt} \%$ was effective for inhibiting crystallization. Other additives were mixed with HAT-CN at a concentration of $10 \mathrm{wt} \%$. Films 5-10 showed transparent appearances as a result of mixing in of the additives. Thus, by mixing with additives, we succeeded in inhibiting crystallization of the solutionprocessed HAT-CN.

\section{Solvent resistances}

To apply the HAT-CN films to solution-processed OLEDs, the films must be resistant to HTL-coating solvents such as $p$-xylene. The films were rinsed in $p$-xylene. The ultraviolet-visible absorption spectra were measured before and after rinsing. The results are summarized in Table 1 and Supplementary Figure S1. After rinsing, absorbance of film 1, composed of only HAT-CN, is almost consistent with that before rinsing, and the bulk of the HAT-CN powder was also almost insoluble in $p$-xylene. The solvent resistances of the other films were also evaluated. Film 2 showed slight film dissolution upon rinsing, whereas films 3 and 4 did not dissolve and showed high solvent resistance. In the case of films containing HATNA-F ${ }_{6}$, films 5 (annealed at $70^{\circ} \mathrm{C}$ ) and 6 (annealed at $180^{\circ} \mathrm{C}$ ) were dissolved in the rinsing solvent. In the case of films containing PPDN, film 7 
(annealed at $70{ }^{\circ} \mathrm{C}$ ) was dissolved in the rinsing solvent, whereas film 8 (annealed at $180^{\circ} \mathrm{C}$ ) surprisingly showed no dissolution. We assumed that the enhanced interaction with PPDN by high temperature annealing provided the film with high solvent resistance characteristics. Films 9 and 10 containing arylamine derivatives dissolved in the rinsing solvent as a result of dissolution of the mixed arylamine derivatives and HAT-CN. In this solvent resistance test, the investigation of annealing temperature effect in HAT-CN mixed with arylamine derivatives has not been performed. Based on these results, in this work, we selected the additives AD-TMP and PPDN for use in HAT-CN as the HIL in solution-processed OLEDs.

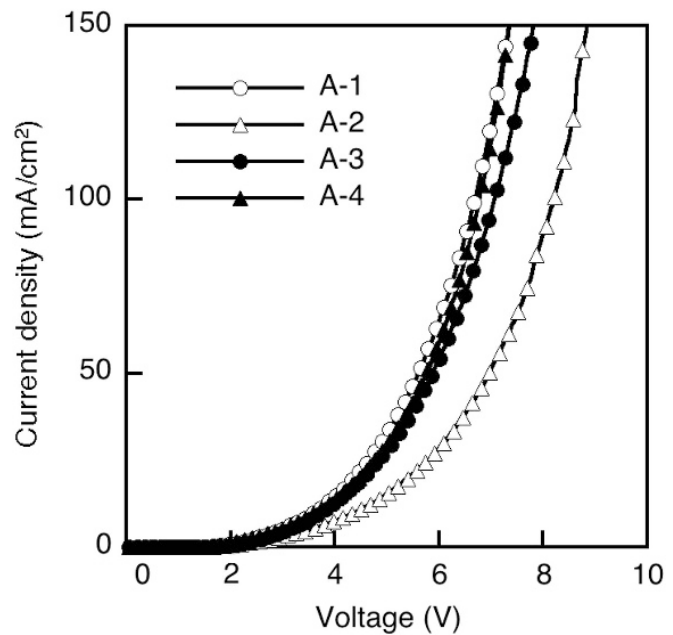

Figure 2 Current density-voltage characteristics of the charge generationonly devices: electron acceptor layers of HAT-CN: 10 wt\% AD-TMP annealed at $70{ }^{\circ} \mathrm{C}$ for $10 \mathrm{~min}$ (device $\mathrm{A} 1$ ) and $180{ }^{\circ} \mathrm{C}$ for $1 \mathrm{~h}$ (device A2), HAT$\mathrm{CN}: 10$ wt $\%$ PPDN annealed at $70{ }^{\circ} \mathrm{C}$ for 10 min (device A3) and $180{ }^{\circ} \mathrm{C}$ for $1 \mathrm{~h}$ (device A4). AD-TMP, ditrimethylol propane tetraacrylate; HAT-CN, 1,4,5,8,9,11-hexaazatriphenylene-hexacarbonitrile; PPDN, pyrazino[2,3-f] $[1,10]$ phenanthroline-2,3-dicarbonitrile.

\section{Charge generation characteristics}

To evaluate the charge generation characteristics, we fabricated CGL-only devices with a structure of (ITO/ZnO $(10 \mathrm{~nm}) /$ HATCN:10 wt $\%$ AD-TMP or PPDN $(10 \mathrm{~nm}) / \alpha-\mathrm{NPD}(100 \mathrm{~nm}) / \mathrm{Al})$. HAT-CN:10 wt $\%$ AD-TMP layers were annealed at $70{ }^{\circ} \mathrm{C}$ for $10 \mathrm{~min}$ (device A-1) or $180^{\circ} \mathrm{C}$ for $1 \mathrm{~h}$ (device A-2). HAT-CN:10 wt \% PPDN layers were annealed at $70^{\circ} \mathrm{C}$ for $10 \mathrm{~min}$ (device A-3) or $180^{\circ} \mathrm{C}$ for $1 \mathrm{~h}$ (device A-4). The electron-transporting $\mathrm{ZnO}$ layer was inserted as the hole injection blocking layer for the ITO anode, and the holetransporting $\alpha$-NPD layer $(100 \mathrm{~nm})$ served as the electron donor and the electron injection blocking layer for the $\mathrm{Al}$ cathode. Figure 2 shows the $J-V$ characteristics of the devices. Devices A-1 and A-4 showed nearly similar behaviors, exhibiting the lowest driving voltages. Device A-2 showed a higher driving voltage than device A-1. Most likely, the high-temperature annealing caused the phase separation of HAT-CN and networked AD-TMP in the film, deteriorating the device characteristics. Conversely, device A-4 showed a lower driving voltage compared with device A-3. Based on the solvent resistance tests of HAT-CN:10 wt\% PPDN, we assume that the high-temperature annealing improved the molecular packing of the film, resulting in lower driving voltages. With regard to the heat resistance of the films, PPDN was superior to AD-TMP as an additive. Then, we evaluated the charge generation characteristics of the devices containing HAT$\mathrm{CN}$ mixed films with arylamine derivatives. The devices were fabricated with the same structure as described above with the exception of the electron acceptor layers. The used electron acceptor layers were HAT-CN mixed with $10 \mathrm{wt} \% \mathrm{~m}$-MTDATA (device A-5), $10 \mathrm{wt} \%$ 4P-NPD (device A-6) and only the evaporated HAT-CN (device A-7). The $J-V$ characteristics of the devices are shown in Supplementary Figure S2. These three devices showed lower driving voltages than device A-4. Among these, device A-7 showed the lowest driving voltage. These results suggested that the charge generation characteristics depend on the type of mixed additives. These additives significantly affected the charge generation characteristics. Unfortunately, these electron acceptor layers containing arylamines did not

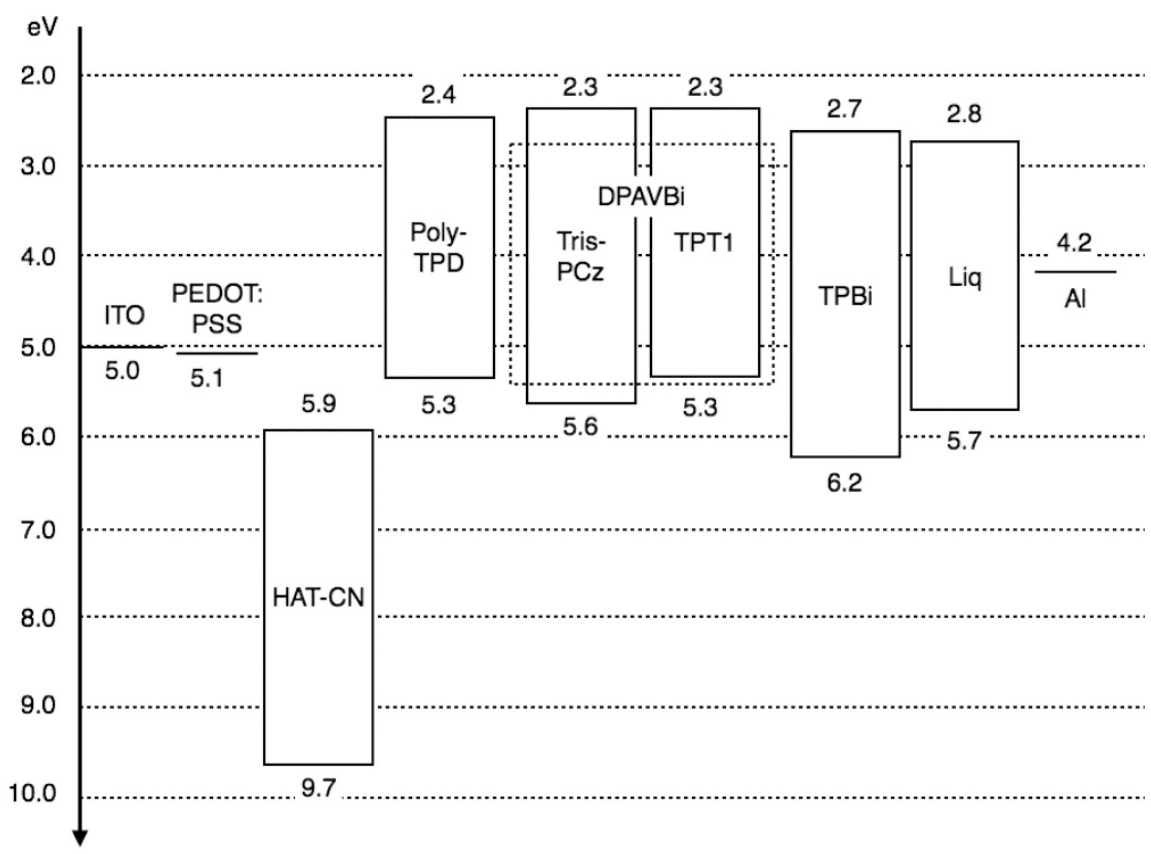

Figure 3 Energy diagram in organic light-emitting devices (OLEDs). 
a

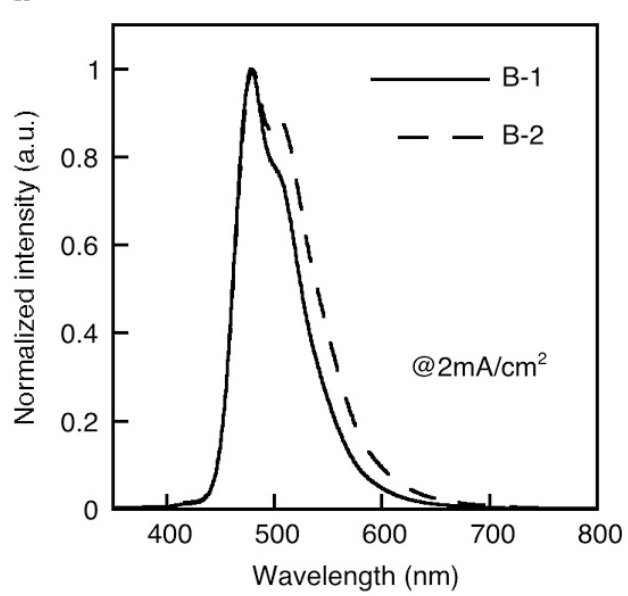

C

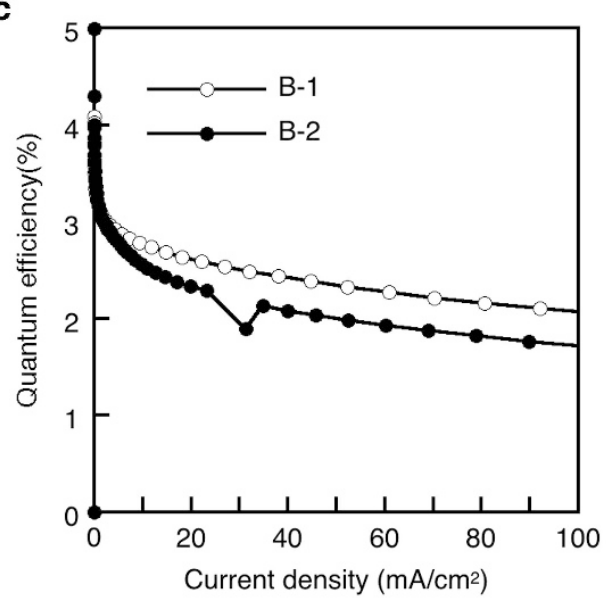

b

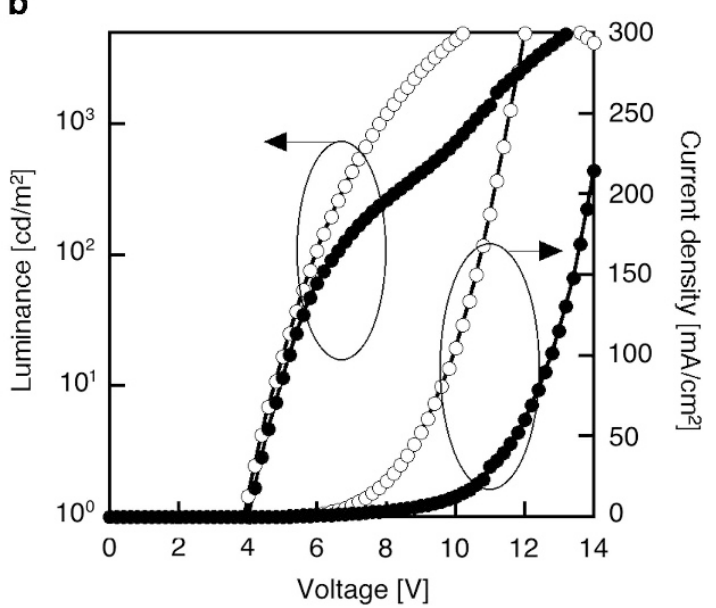

d

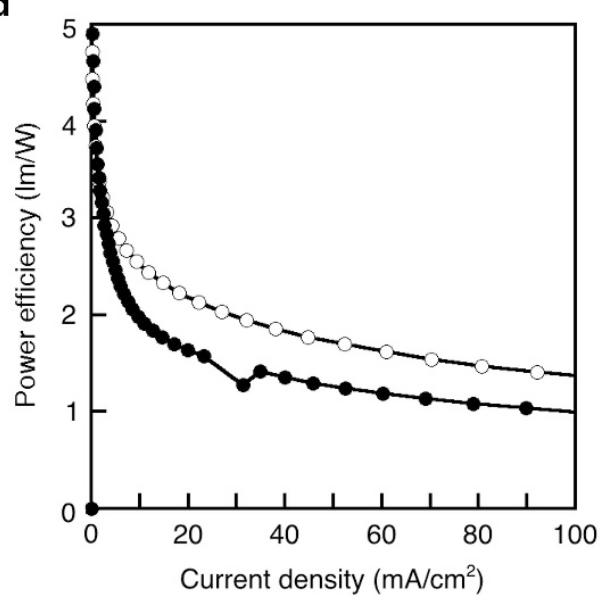

Figure 4 Organic light-emitting device (OLED) characteristics: (a) electroluminescence (EL) spectra at $2 \mathrm{~mA} \mathrm{~cm}^{-2}$, (b) current density-voltage-luminance, (c) current density-quantum efficiency and (d) current density-power efficiency characteristics.

show solvent resistance, and therefore, they could not be applied to solution-processed OLEDs.

\section{Application of HIL in OLED}

We fabricated a solution-processed blue fluorescent OLED with an HIL comprising HAT-CN and PPDN additive and compared it with the corresponding OLED containing PEDOT:PSS as the HIL. The device structure was (ITO/HAT-CN:10 wt\% PPDN $(10 \mathrm{~nm})$ (device B-1) or PEDOT:PSS (30 nm) (device B-2)/poly-TPD $(40 \mathrm{~nm}) / 10 \mathrm{wt} \%$ DPAVBi:TPT1:TrisPCz $(30 \mathrm{~nm}) / \mathrm{TPBi}(50 \mathrm{~nm}) / \mathrm{Liq}$ $(3 \mathrm{~nm}) / \mathrm{Al})$. With the exception of Liq and $\mathrm{Al}$ layers formed by evaporation under vacuum, all layers were formed by the spin-coating method. We selected each layer material based on the point of view of solvent resistances of the materials to the corresponding upper layer coating solvents. TPBi dissolves well in methanol. In contrast, TrisPCz has a high resistance to methanol. ${ }^{35}$ TPT1 was further added to improve the hole-transporting property. TrisPCz and TPT1 can dissolve in the coating solvent. Poly-TPD shows a high resistance to the coating solvent. ${ }^{36}$ The energy diagram of the fabricated devices is shown in Figure 3. Here, we used the averages of the reported energy level values for HAT-CN..$^{30,31}$ The electroluminescence spectra, current density-voltage-luminance, current density-external quantum efficiency and current density-power efficiency characteristics are shown in Figure 4. Device B-1 showed a significantly lower driving voltage than device B-2. The current density-external quantum efficiency of device B-1 was also higher than that of device B-2. As a result, the power efficiency of device B-1 was also higher than that of device B-2. The slightly different electroluminescence spectra shapes probably resulted from the differences in total thicknesses and charge recombination positions in the devices. The HAT-CN:10 wt\% PPDN HIL showed better performance than the PEDOT:PSS HIL. These results clearly reveal that the HAT-CN mixed with additives serves as a highly effective HIL for solution-processed OLEDs.

\section{CONCLUSIONS}

We demonstrated the usefulness of the HAT-CN mixed with additives as an HIL in solution-processed OLEDs. The mixed additives inhibited the crystallization of HAT-CN during the solution process in the films. Among the mixtures with additives, AD-TMP and PPDN mixed films showed high solvent resistances to $p$-xylene. The charge generation characteristics of HAT-CN mixed with AD-TMP, PPDN and $\alpha$-NPD were evaluated and compared. Thus, the HAT-CN mixed with PPDN showed better characteristics and a high heat resistance. A solution-processed blue fluorescent OLED with a HAT-CN mixed with PPDN as HIL was fabricated. The device with a HAT-CN mixed with PPDN showed a lower driving voltage and higher luminescent efficiency than the devices containing PEDOT:PSS. These results 
demonstrated the high usefulness of the HAT-CN mixed with additives as an HIL for solution-processed OLEDs.

\section{CONFLICT OF INTEREST}

The authors declare no conflict of interest.

\section{ACKNOWLEDGEMENTS}

We thank the 'Strategic Promotion of Innovative R\&D Program' of Japan Science and Technology Agency (JST) for financial support.

1 Kido, J., Kimura, M. \& Nagai, K. Multilayer white light-emitting organic electroluminescent device. Science 267, 1332-1334 (1995).

2 Sasabe, H. \& Kido, J. Recent progress in phosphorescent organic light-emitting devices. Eur. J. Org. Chem. 2013, 7653-7663 (2013).

3 Sasabe, H. \& Kido, J. Development of high performance OLEDs for general lighting. J. Mater. Chem. C 1, 1699 (2013).

4 Cho, S. H., Pyo, S. W. \& Suh, M. C. Low voltage top-emitting organic light emitting devices by using 1,4,5,8,9,11-hexaazatriphenylene-hexacarbonitrile. Synth. Met. 162 402-405 (2012).

5 Choi, H., Kim, B., Ko, M. J., Lee, D.-K., Kim, H., Kim, S. H. \& Kim, K. Solution processed WO3 layer for the replacement of PEDOT:PSS layer in organic photovoltaic cells. Org. Electron. 13, 959-968 (2012).

6 Choudhury, K. R., Lee, J., Chopra, N., Gupta, A., Jiang, X., Amy, F. \& So, F. Highly efficient hole injection using polymeric anode materials for small-molecule organic light-emitting diodes. Adv. Funct. Mater. 19, 491-496 (2009).

7 Ho, S., Xiang, C., Liu, R., Chopra, N., Mathai, M. \& So, F. Stable solution processed hole injection material for organic light-emitting diodes. Org. Electron. 15, 2513-2517 (2014)

8 Hofle, S., Bruns, M., Strassle, S., Feldmann, C., Lemmer, U. \& Colsmann, A. Tungsten oxide buffer layers fabricated in an inert sol-gel process at room-temperature for blue organic light-emitting diodes. Adv. Mater. 25, 4113-4116 (2013).

9 Ito, T., Asaka, J., Dao, K. L. T. \& Kido, J. Organic light-emitting devices having chemically-doped arylamine oligomer as a hole injection layer. Polym. Adv. Technol. 16, 559-562 (2005).

10 Jiang, F., Choy, W. C., Li, X., Zhang, D. \& Cheng, J. Post-treatment-free solutionprocessed non-stoichiometric $\mathrm{NiO}(\mathrm{x})$ nanoparticles for efficient hole-transport layers of organic optoelectronic devices. Adv. Mater. 27, 2930-2937 (2015).

11 Meyer, J., Khalandovsky, R., Gorrn, P. \& Kahn, A. MoO3 films spin-coated from a nanoparticle suspension for efficient hole-injection in organic electronics. Adv. Mater. 23, 70-73 (2011).

12 Perumal, A., Faber, H., Yaacobi-Gross, N., Pattanasattayavong, P., Burgess, C., Jha, S., McLachlan, M. A., Stavrinou, P. N., Anthopoulos, T. D. \& Bradley, D. D. Highefficiency, solution-processed, multilayer phosphorescent organic light-emitting diodes with a copper thiocyanate hole-injection/hole-transport layer. Adv. Mater. 27, 93-100 (2015)

13 Tokito, S., Noda, K. \& Taga, Y. Metal oxides as a hole-injecting layer for an organic electroluminescent device. J. Phys. D Appl. Phys. 29, 2750-2753 (1996).

14 Zhou, J., Anjum, D. H., Chen, L., Xu, X., Ventura, I. A., Jiang, L. \& Lubineau, G. The temperature-dependent microstructure of PEDOT/PSS films: insights from morphological, mechanical and electrical analyses. J. Mater. Chem. C 2, 9903-9910 (2014).

15 Ohisa, S., Kagami, S., Pu, Y.-J., Chiba, T. \& Kido, J. A solution-processed heteropoly acid containing $\mathrm{MoO} 3$ units as a hole-injection material for highly stable organic lightemitting devices. ACS Appl. Mater. Interfaces 8, 20946-20954 (2016).

16 Chiba, T., Pu, Y.-J., Miyazaki, R., Nakayama, K., Sasabe, H. \& Kido, J. Ultra-high efficiency by multiple emission from stacked organic light-emitting devices. Org. Electron. 12, 710-715 (2011).

17 Cui, L. S., Xie, Y. M., Wang, Y. K., Zhong, C., Deng, Y. L., Liu, X. Y., Jiang, Z. Q. \& Liao, L. S. Pure hydrocarbon hosts for approximately $100 \%$ exciton harvesting in both phosphorescent and fluorescent light-emitting devices. Adv. Mater. 27, 4213-4217 (2015).

$18 \mathrm{Kim}, \mathrm{D} . \mathrm{H}$. \& Kim, T. W. Efficiency enhancement in tandem organic light-emitting devices with a hybrid charge generation layer composed of BEDT-TTF-doped TPBi/mCP/ HAT-CN. Org. Electron. 15, 3452-3457 (2014).

19 Liao, L. S. \& Klubek, K. P. Power efficiency improvement in a tandem organic lightemitting diode. Appl. Phys. Lett. 92, 223311 (2008).

20 Liao, L. S., Slusarek, W. K., Hatwar, T. K., Ricks, M. L. \& Comfort, D. L. Tandem organic light-emitting diode using hexaazatriphenylene hexacarbonitrile in the intermediate connector. Adv. Mater. 20, 324-329 (2008).

21 Lin, H.-W., Lin, W.-C., Chang, J.-H. \& Wu, C.-I. Solution-processed hexaazatriphenylene hexacarbonitrile as a universal hole-injection layer for organic light-emitting diodes. Org. Electron. 14, 1204-1210 (2013).

22 Son, S.-H., Kim, O.-H., Yoon, S.-H., Kim, K.-K., Lee, Y.-G. \& Bae, J.-S. Electronic device comprising organic compound having $\mathrm{p}$-type semiconducting characteristics. USPatent 6,720,573 B2 (2004).

23 Kanakarajan, K. \& Czarnik, A. W. Synthesis and some reactions of hexaazatriphenylenehexacarbonitrile,a hydrogen-free polyfunctional heterocycle with Dah symmetry. J. Org. Chem. 51, 5241-5243 (1986).

24 Broker, B., Hofmann, O. T., Rangger, G. M., Frank, P., Blum, R. P., Rieger, R., Venema, L., Vollmer, A., Mullen, K., Rabe, J. P., Winkler, A., Rudolf, P., Zojer, E. \& Koch, N. Density-dependent reorientation and rehybridization of chemisorbed conjugated molecules for controlling interface electronic structure. Phys. Rev. Lett. 104, 246805 (2010).

25 Chifotides, H. T., Schottel, B. L. \& Dunbar, K. R. The pi-accepting arene HAT(CN)6 as a halide receptor through charge transfer: multisite anion interactions and self-assembly in solution and the solid state. Angew. Chem. Int. Ed. 49, 7202-7207 (2010).

26 Gallegos, J. R., Francis, A. H., Ockwig, N. W., Rasmussen, P. G., Raptis, R. G., Challen, P. R. \& Ouedraogo, I. The spectroelectrochemical, magnetic, and structural characterization of reduced hexaazatriphenylenehexacarbonitrile, HAT(CN)6. Synth. Met. 159, 1667-1671 (2009).

27 Saragi, T. P. I., Reichert, T., Scheffler, A., Kussler, M. \& Salbeck, J. Electron mobility in hexaazatriphenylene hexacarbonitrile field-effect transistors. Synth. Met. 162, 1572-1576 (2012)

28 Szalay, P. S., Galán-Mascarós, J. R., Clérac, R. \& Dunbar, K. R. HAT(CN)6: a new building block for molecule-based magnetic materials. Synth. Met. 122, 535-542 (2001).

29 Szalay, P. S., Galán-Mascarós, J. R., Schottel, B. L., Bacsa, J., Pérez, L. M., Ichimura, A. S., Chouai, A. \& Dunbar, K. R. Experimental and computational studies of charge-transfer and reduction products of 1,4,5,8,9,11-hexaazatriphenylene-hexacarbonitrile: HAT-(CN)6. J. Cluster Sci. 15, 503-530 (2004).

$30 \mathrm{Kim}$, Y.-K., Won Kim, J. \& Park, Y. Energy level alignment at a charge generation interface between 4,4[sup 1-bis(N-phenyl-1-naphthylamino)biphenyl and 1,4,5,8,9,11-hexaazatriphenylene-hexacarbonitrile. Appl. Phys. Lett. 94 , 063305 (2009).

31 Park, S. M., Kim, Y. H., Yi, Y., Oh, H.-Y. \& Won Kim, J. Insertion of an organic interlayer for hole current enhancement in inverted organic light emitting devices. Appl. Phys. Lett. 97, 063308 (2010).

32 Barlow, S., Zhang, Q., Kaafarani, B. R., Risko, C., Amy, F., Chan, C. K., Domercq, B., Starikova, Z. A., Antipin, M. Y., Timofeeva, T. V., Kippelen, B., Bredas, J. L., Kahn, A. \& Marder, S. R. Synthesis, ionisation potentials and electron affinities of hexaazatrinaphthylene derivatives. Chem. Eur. J. 13, 3537-3547 (2007).

33 Chiba, T., Pu, Y. J., Hirasawa, M., Masuhara, A., Sasabe, H. \& Kido, J. Solutionprocessed inorganic-organic hybrid electron injection layer for polymer light-emitting devices. ACS Appl. Mater. Interfaces 4, 6104-6108 (2012).

34 Sun, B. \& Sirringhaus, H. Solution-processed zinc oxide field-effect transistors based on self-assembly of colloidal nanorods. Nano Lett. 5, 2408-2413 (2005).

35 Aizawa, N., Pu, Y.-J., Watanabe, M., Chiba, T., Ideta, K., Toyota, N., Igarashi, M., Suzuri, Y., Sasabe, H. \& Kido, J. Solution-processed multilayer small-molecule lightemitting devices with high-efficiency white-light emission. Nat. Commun. 5, 5756 (2014).

36 Ohisa, S., Pu, Y.-J., Yamada, N. L., Matsuba, G. \& Kido, J. Molecular interdiffusion between stacked layers by solution and thermal annealing processes in organic light emitting devices. ACS Appl. Mater. Interfaces 7, 20779-20785 (2015).

Supplementary Information accompanies the paper on Polymer Journal website (http://www.nature.com/pj) 